\title{
Effect of Memorable Tourism Experiences on Revisit Intention to Community-Based Tourism Destination of Domestic Tourists in Vietnam
}

\author{
Huyen Tran \\ Thai Nguyen University of Technology \\ Thai Nguyen University \\ Thai Nguyen, Viet Nam \\ tranthithuhuyen@tnut.edu.vn
}

\begin{abstract}
The intention to return to a destination is one of the important research topics in tourism. The antecedents of revisiting intention confirmed include trip satisfaction, destination image, tourist attitude, and, most recently, memorable tourism experiences. This study tests the hypothesis of the impact of memorable tourism experience components on the intention to revisit the destination of domestic tourists in the community-based tourism in Northern Vietnam. The memorable tourism experience components are adapted from the scale of Kim et al [16], Chandaral et al [6], and Coudounaris et al [9]. The study carried out exploratory factor analysis (EFA), confirmatory factor analysis (CFA), and finally, linear structural equation model analysis (SEM). It confirmed eight components of memorable tourism experiences that positively influence the intention to revisit domestic tourists and do not support the hypothesis that adverse feeling experiences affect revisit intention. There is no difference in intention to revisit the CBT destination between gender groups and different age groups with the research sample obtained.
\end{abstract}

Index Terms-community-based tourism, destination, domestic tourists, memorable tourism experiences, revisit intention.

\section{Introduction}

$\mathrm{P}$ NE and Gilmore argue that the world is shifting towards an experience economy, and what businesses provide to their customers are designed experiences [24]. The tourism industry has been a pioneer in emphasizing the tourists' experience. Memorable travel experiences have been a topic of great interest since more than a decade ago. Quite a few studies show that this is a factor that directly impacts the behavioral intention of tourists. [7], [13], [14].

Community-based tourism is growing in Asian countries, including Vietnam. According to Nicole Hausler and Wolfgang Strasdas: "CBT is a form of tourism that mainly local people develop and manage."

Relying on the advantages of natural scenery and local culture, community-based tourism destinations in North Vietnam have attracted many domestic and international tourists. The research on community-based tourism experiences in Vietnam is quite limited, and especially there has not been much attention on the memorable tourism experiences and the relationship between revisit intention to the destination and memorable tourism experiences. This study was conducted to clarify this issue in the literature review further.

\section{Literature Review And Hypotheses Development}

\section{A. Memorable Tourism Experiences}

Memorable Tourism Experiences (MTEs) and the relationship between memorable tourism experiences and intention to revisit are topics of great interest from tourism experience scholars. Many studies have suggested that tourism experience is a subjective mental state perceived by tourists [20], [24] and exists in their perception or emotions [23], [26]. However, not every experience can be remembered for long. The relationship between memory and experience has been studied for a long time and has been confirmed in the studies of Arnold \& Price [2], Quinlan Culter \& Carmichael [26]. According to Kim, there are three different groups of factors affecting human memory ability that have been recorded in previous studies [18]. First, the more emotionally connected events are, the better they are remembered, and the higher the emotional level, the clearer the recall. Second, cognitive assessment (understood as a semantic analysis of the situation/ event, a post-examination process that enriches or details the initial effects) increases recalled memories. Third, extraordinary events are better remembered than ordinary events. Based on that, the research group of Kim, Tung, and Ritchie has delved into the study of memorable tourism experiences and the antecedents and consequences of MTEs. Research results show that MTEs are formed from the experiences that tourists have through interactions during the trip and that MTEs are different for each person. In a 2012 study, Kim et al suggested that MTEs are experiences that tourists gain after a trip, are remembered and can be recalled after that trip.

MTEs are formed from tourism experiences. Therefore, MTEs are also affected by factors affecting tourism experience, including anything we can physically experience (landscape, plants, animals, weather, buildings, and other infrastructure...), social factors (culture, all relationships between tourists and tour guides, locals...), tourism services and products (transport services, hotels, food, services) medical, souvenirs ...) as well as internal factors of tourists: motivation, pretensions about the trip, tourists' understanding, ability to remember, self-awareness, and personal identity [26]. Tourism experience is said to have many different aspects, but only some aspects can be deeply remembered by tourists [6], [16], [24], [20]. Scholars reviewed a range of studies related to remembering previous experiences and recounted the components mentioned in previous studies. Based on the known components, they conduct qualitative research to discover and confirm the 
components of MTEs before constructing a scale and putting them to the test: Hedonism, Relaxation, Stimulation, Refreshment, Adverse feelings, Social interaction, Happiness, Meaningfulness, Knowledge, Unexpected happenings, Personal relevance, Novelty ... It is worth noting that until Kim's study [16], no study has looked at all components of MTEs at once, and most previous studies have evaluated only one or a few memorized components of the tourism experience. Several previous studies have investigated the structure and factors that influence MTEs... Kim et al. and Chandarla et al. conducted studies to identify the memorable components of travel experiences in different contexts [16], [6]. Kim et al. introduced a 7-component MTEs scale, using 24 indicators [16]. Chandaral et al. introduced a 10-component MTEs scale, using 34 indicators [6]. Later studies have shown that MTEs have different components with different contexts. Ayazlar et al. tested Kim et al.'s scale with two groups of tourists from two different cultures [3], England and Turkey, visiting the same destination, Didim, Turkey, shows that the composition of memorable tourism experiences of these two groups is different. British tourists generally find local culture and knowledge more memorable, while hedonism and involvement are the most memorable components of the travel experience of Turkish tourists. This result shows differences in the memorable levels of components in different cultures.

\section{B. Tourist's revisit intention and impact of MTEs on revisit intention.}

Baker and Crompton argue that a tourist's revisit intention is a tourist's willingness to visit a destination again and also argue that this behavior is an expression of customer loyalty, similar to a willingness to repurchase a product [4]. Thus, the revisit intention in tourism can be understood as the ability of tourists to revisit the destination in the future. Kozak states that tourists' revisit intention is the expression of willingness to visit a particular destination or other destinations within the same country [19]. Other authors suggest that the intention to revisit a destination is expressed through the willingness to recommend the destination to relatives and friends [1]. Revisit intention has been considered an important research topic in scientific research and the tourism industry [12]. From the early twenty-first century, there has been quite a bit of research on intention to revisit tourist destinations to predict and explain their intention in making travel decisions [19], [31], [12], [11], [32]. The antecedent factors of revisit intention include emotion, satisfaction, attitude, previous experience, perception of the destination, and recently a memorable tourism experience.

Means-End Chain Theory (Means-End Chain - MEC) was developed by Gutman from applying value perspectives to the marketing of consumer products, focusing on the association between attributes that exist in the product, the consequences of those attributes, and the values the individual customer derives from those consequences. MEC theory holds that consumers decide to use a product/service not based on the benefits of the product/service itself but because they can achieve the desired benefits and values through these products/services. Therefore, consumers will make decisions based on the final values they feel after experiencing the attributes of the product/service. The last perceived value mentioned above is the memorable tourism experiences of visitors. According to the Mean-Ends series theory, memorable tourist experiences influence tourists' subsequent choices, manifest through behavioral intention.

Many different studies have confirmed the positive impact of memorable tourism experiences on revisit intention a destination. In different contexts, memorable tourism experience components have different influences on revisit intention. Kim suggests that three components: enjoyment, participation, and local culture, have a positive impact on the intention to revisit tourists [18]. Sthapit used MTEs scale of $\mathrm{Kim}$ et al. to find memorable tourism experiences with a survey sample of tourists who visited Rovaniemi [27]. Research results show that local culture and novelty significantly influence tourists' intention to return to a destination. Chandralal and Valenzuela developed their scale and analyzed the relationship between the components of a memorable tourist experience and the intention to revisit [7]. Their findings showed that novelty travelers are not likely to revisit similar sites in that country but will often recommend them to others. Although studies on the impact of memorable tourism experiences on intention to return to a destination have been inconsistent in determining which components of a memorable tourism experience have a positive impact on the revisit intention of tourists, the positive impact on tourists' intention to revisit the destination is an argument that many studies have been reinforced. Therefore, considering the context of CBT in Vietnam, the following hypothesis is proposed:

H1: Remembered hedonism experiences positively impact the revisit intention of domestic tourists to the destination.

H2: Remembered refreshment experiences positively impact the revisit intention of domestic tourists to the destination.

H3: Remembered novelty experiences positively impact the revisit intention of domestic tourists to the destination.

H4: Remembered involvement experiences positively impact the revisit intention of domestic tourists to the destination

H5: Remembered surprising experiences positively impact the revisit intention of domestic tourists to the destination

H6: Remembered meaningfulness experiences positively impact the revisit intention of domestic tourists to the destination.

H7: Remembered knowledge experiences positively impact the revisit intention of domestic tourists to the destination

H8: Remembered local culture experiences positively impact the revisit intention of domestic tourists to the destination.

H9: Remembered adverse feeling experiences negatively impact the revisit intention of domestic tourists to the destination. 


\section{METHOD}

\section{A. Context}

Community-based tourism development in Vietnam, in general, is still limited [10]. People and local authorities in many places still have problems developing products that are attractive to tourists, and at the same time, associated with the protection and development of local tangible and intangible resources. In the Vietnam northern mountainous region, Sapa and Mai Chau have a relatively large and stable number of tourists, while other community-based tourist destinations in Lang Son, Ha Giang, Cao Bang, Lai Chau, Dien Bien ... are still inefficient and straightforward [8], [29]. Community-based tourism destinations in Vietnam proliferate, but most tourism experience designs are not distinctive. It is also why the rate of tourists returning to community-based tourism destinations is lower in Vietnam than in some countries in Southeast Asia.

\section{B. Participants and procedure}

Before conducting the survey, we asked participants to recall the most memorable tourism experience with a CBT destination and recall the number of companions on the trip. Based on this recollection, they completed a 32-item scale on MTEs and a 4-item scale on revisit intention and provided additional demographic information. Out of the collected 458 questionnaires, we excluded 53 invalid questionnaires and left 405 valid responses for the analytical data.

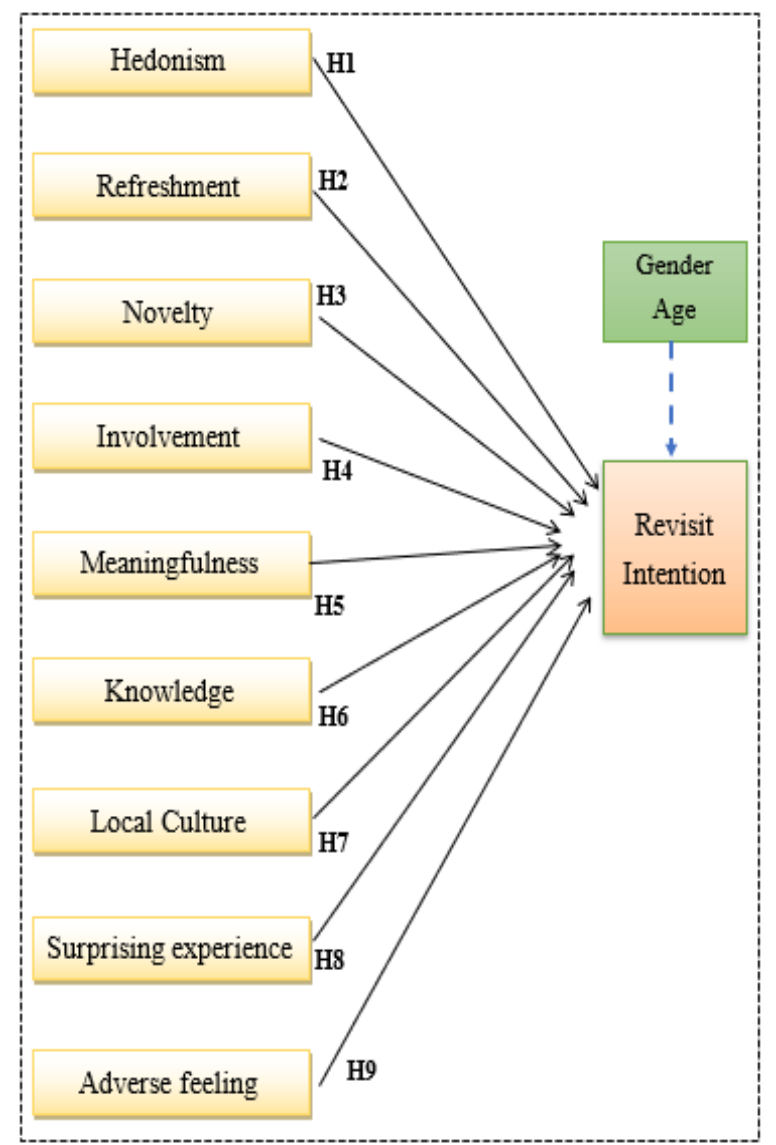

Figure 1: Research model
The sample was selected by snowball sampling and convenience sampling. Each survey participant will be asked to send the survey to about five other people who already have MTEs in community-based tourism in Vietnam. Among the participants, $66.9 \%$ were male while $33.1 \%$ were female; $25.4 \%$ were $18-25$ years old, $22.5 \%$ were $26-35$ years old, $49.4 \%$ were $36-50$ years old, and $2.7 \%$ were 51 years old and older. Of these, 272 people traveled in small groups ( 7 people or less), and 133 travel in large groups (8 people or more). Table 1 presents Sample Characteristics in greater detail.

Table 1. Sample Characteristics

\begin{tabular}{|c|l|l|}
\hline Variable & \multicolumn{1}{|c|}{ Category } & \multicolumn{1}{c|}{ Distribution } \\
\hline Gender & Male & $271(66.9 \%)$ \\
& Female & $134(33.1 \%)$ \\
\hline Age & 18 to less than 25 & $103(25.4 \%)$ \\
& 25 to less than 35 & $91(22.5 \%)$ \\
& 35 to less than 50 & $200(49.4 \%)$ \\
& more than 50 & $11(2.7 \%)$ \\
\hline Earnings & Less than 5 & $68(16.8 \%)$ \\
(Million & 5 to less than 9 & $119(29.4 \%)$ \\
VND) & 9 to less than 14 & $116(28.6 \%)$ \\
& 14 to less than 27 & $61(15.1 \%)$ \\
& More than 27 & $41(10.1 \%)$ \\
\hline
\end{tabular}

\section{Questionnaires}

The survey questionnaire has three parts. The detailed information of respondents is the first part. The next is tourists' reviews of the MTEs they have had, and part 3 is the questions related to the revisit intention of tourists. The author adapted the scales suggested by previous studies to suit the research context.

The MTEs scale is adapted from the seven components scale introduced by Kim et al. with the addition of the "Surprising experience" component from the Chandaral scale and the "Adverse feeling" component from Coudounaris et al. [16], [6], [9]. Thus, MTEs are measured using nine components (32 items). Thirty items are adapted from the original scales, and two new items are proposed. Four items for revisit intentions were adopted from the study of Kim et al. The questionnaire uses the Likert scale with five levels, from low to high scores, ranging from 1-5: 1. Strongly disagree; 2. Disagree; 3. Normal; 4. Agree; 5. Strongly agree. D. Data analysis

All data were analyzed by SPSS 25.0 and AMOS 20.0 after being collected. Following Anderson and Gerbing's (1988) recommended procedure, the construct's reliability, convergent validity, and discriminant validity were tested before testing the structural model. The scale's reliability is tested by Cronbach's Alpha coefficient (a measure of internal consistency). Then, the study conducted exploratory factor analysis (EFA) to evaluate the factor structure of the measures and check their reliability. The formal evaluation of the scale to analyze the validity of the model was conducted based on confirmatory factor analysis (CFA). Finally, due to the relationship between the independent variables (interaction between feelings and emotions, evaluated in the formating of MTEs), the study tested the hypotheses by analysis of structural equation modeling (SEM) to be able to visually check the relationships that exist 
between the variables of interest. SEM also facilitates multigroup analyzes that can be carried out in the following studies (if any). increased from 0.737 to 0.823 . Therefore, all scales are eligible for EFA analysis.

Table 2: Measurement scale and construction source

\begin{tabular}{|c|c|c|c|}
\hline Scale & Encode & Question & Source \\
\hline \multirow{4}{*}{$\begin{array}{c}\text { Hedonism } \\
\text { (TANHUONG) }\end{array}$} & TANHUONG4 & Exciting & \multirow{4}{*}{ Kim et al. [16] } \\
\hline & TANHUONG3 & I really enjoyed this tourism experience. & \\
\hline & TANHUONG2 & Indulged in the activities & \\
\hline & TANHUONG1 & Thrilled about having a new experience & \\
\hline \multirow{4}{*}{$\begin{array}{c}\text { Novelty } \\
\text { (DOCDAO) }\end{array}$} & DOCDAO4 & Experienced something new & \multirow{4}{*}{ Kim et al. [16] } \\
\hline & DOCDAO3 & Different from previous experiences & \\
\hline & DOCDAO2 & Unique & \\
\hline & DOCDAO1 & Once-in-a-lifetime experience & \\
\hline \multirow{4}{*}{$\begin{array}{l}\text { Refreshment } \\
\text { (THUGIAN) }\end{array}$} & THUGIAN4 & Revitalized & \multirow{4}{*}{ Kim et al. [16] } \\
\hline & THUGIAN3 & Refreshing & \\
\hline & THUGIAN2 & I enjoyed the sense of freedom. & \\
\hline & THUGIAN1 & Liberating & \\
\hline \multirow{4}{*}{$\begin{array}{l}\text { Meaning- } \\
\text { fulness } \\
\text { (YNGHIA) }\end{array}$} & YNGHIA4 & I was inspired & \multirow{4}{*}{$\begin{array}{c}\text { Kim et al. [16] } \\
\text { and author's } \\
\text { proposal }\end{array}$} \\
\hline & YNGHIA3 & Learned about myself & \\
\hline & YNGHIA2 & I did something important. & \\
\hline & YNGHIA1 & I did something meaningful. & \\
\hline \multirow{3}{*}{$\begin{array}{l}\text { Knowledge } \\
\text { (KIENTHUC) }\end{array}$} & KIENTHUC1 & Exploratory & \multirow{3}{*}{ Kim et al. [16] } \\
\hline & KIENTHUC2 & Knowledge & \\
\hline & KIENTHUC3 & New culture & \\
\hline \multirow{3}{*}{$\begin{array}{l}\text { Involvement } \\
\text { (THAMGIA) }\end{array}$} & THAMGIA1 & I visited a place where I really wanted to go. & \multirow{3}{*}{ Kim et al. [16] } \\
\hline & THAMGIA2 & I enjoyed activities which I really wanted to do. & \\
\hline & THAMGIA3 & I was interested in the main activities of this trip. & \\
\hline \multirow{4}{*}{$\begin{array}{l}\text { Local culture } \\
\text { (VANHOA) }\end{array}$} & VANHOA1 & Good impressions about the local people. & \multirow{4}{*}{$\begin{array}{c}\text { Kim et al. [16]\& } \\
\text { author's } \\
\text { proposal }\end{array}$} \\
\hline & VANHOA2 & Closely experienced the local culture. & \\
\hline & VANHOA3 & Local people in a destination were friendly. & \\
\hline & VANHOA4 & I really like the local food culture. & \\
\hline \multirow{3}{*}{$\begin{array}{l}\text { Surprising } \\
\text { experience } \\
\text { (BATNGO) }\end{array}$} & BATNGO1 & Unexpected good incidents, experiences during the trip & \multirow{3}{*}{ Chandaral [6] } \\
\hline & BATNGO2 & Certain random things that surprised me during the trip & \\
\hline & BATNGO3 & Unexpected benefits or advantages during the trip & \\
\hline \multirow{3}{*}{$\begin{array}{c}\text { Adverse } \\
\text { feeling } \\
\text { (TIEUCUC) }\end{array}$} & TIEUCUC1 & I was angry during the trip & \multirow{3}{*}{$\begin{array}{c}\text { Coudounaris et } \\
\text { al [9] }\end{array}$} \\
\hline & TIEUCUC2 & I was frustrated during the trip. & \\
\hline & TIEUCUC3 & I was embarrassed during the trip. & \\
\hline \multirow{4}{*}{$\begin{array}{l}\text { Revisit } \\
\text { Intention } \\
\text { (YDINH) }\end{array}$} & YDINH1 & I want to revisit the CBT destination in the future & \multirow{4}{*}{ Kim et al [16] } \\
\hline & YDINH2 & I plan to revisit the CBT destination in the future. & \\
\hline & YDINH3 & I will make an effort to revisit the CBT destination in the future. & \\
\hline & YDINH4 & I would like to visit similar CBT destinations in the future. & \\
\hline
\end{tabular}

\section{RESEARCH RESULTS AND DISCUSSION}

\section{A. Assess the reliability of the scales}

According to Nunnally, the appropriate scale must have Cronbach's Alpha reliability greater than or equal to 0.7 . Hair et al. also suggested that the scale to ensure unidirectionality and reliability should reach Cronbach's Alpha threshold of 0.7 or higher. The analysis results show that all variables have Cronbach's alpha coefficients above 0.7. All values in column Corrected Item - Total Correlation is more significant than 0.3 , except for the observed variable DOCDAO1, which has a total correlation coefficient of 0.253 . Thus, the observed variable DOCDAO1 is excluded from the research model. After removing this variable, the Cronbach's Alpha coefficient of the Novelty variable

\section{B. Exploratory Factor Analysis}

The study used PDF extraction with Promax perpendicular rotation method to summarize the observed variables included in factor analysis and help reduce the number of many observations to a smaller number of main factors for CFA test analysis and SEM linear model. The breakpoint of the EFA analysis is set based on the Eigenvalue coefficient with the number of extracted factors having an Eigenvalue of 1 or more.

The results of the first EFA showed that the observed variable THUGIAN4 uploaded to the 4th factor is not strong enough (Factor loading $=0.498<0.5$ ). Therefore, the author removed the observed variable THUGIAN4 from the model. The results of the second EFA show that: KMO coefficient is 
equal to $0.884>0.5$. According to Kaiser, using this data set for factor analysis is appropriate. Bartlett's test is also satisfactory with Sig. $=0.00<0.05$. The number of factors extracted here is 10 , corresponding to the Eigenvalue coefficient stopping at 1,007 , and the total variance extracted is $61.152 \%>60 \%$.

\section{Confirmatory Factor Analysis (CFA)}

According to the analysis results above, the component scales of memorable tourism experiences: Enjoyment, relaxation, originality, significance, participation, surprise, local culture, knowledge, negative emotions, and intention to return to the destination were tested by CFA. The results of CFA analysis of all scales have good indicators that reflect the goodness of fit of the model, specifically: CMIN/DF = 1,$070 ; \mathrm{GFI}=0.933 ; \mathrm{CFI}=0.995 ; \mathrm{TLI}=0.994 ; \mathrm{RMSEA}=$ $0.013 ;$ PCLOSE $=1,000$.

Thus, according to $\mathrm{Hu} \&$ Bentler, the model fits the data. The normalized weights of the model all have a value greater than 0.5 , range from 0.686 to 0.856 , and reach statistical significance with $\mathrm{p}=0.000<0.05$. Therefore, all observed variables have meaning in the scale.". Based on normalized regression weights, the reliability, convergence, and discriminant indexes are calculated in Table 3. CR values are greater than 0.7 , so the scales are reliable. The AVE values are all greater than 0.5 , so the scales are all convergent. MSV values are smaller than AVE, so the discriminant of the scales is confirmed.

\section{Differences in revisiting intention to $C B T$ destinations across gender and age groups}

The study used independent Sample T-Test and one-way ANOVA analysis to test the difference in intention to revisit destinations between men and women; between different age groups (shown in Table 1). Sig Levene's Test is equal to $0.984>0.05$. Sig t-test equals $0.991>0.05$, so there is no difference in intention between different sex groups. Sig Levene's Test is equal to $0.755>0.05$. Sig F-test is $0.303>$ 0.05 , so there is no difference in intention between respondents of different ages. With the current sample of observations, the intention to revisit the CBT destination is not controlled for the gender and age variables.

\section{E. Structural Equation Modeling (SEM) analysis and hypothesis testing}

The study uses Structural Equation Modeling (SEM) analysis to assess the impact between the factors in the proposed research model. From the results of analysis by SEM, the study evaluated the model's suitability through Chi-square/ df, CFI, IFI, RMSEA indexes and tested two hypotheses. The model's indexes are satisfactory, specifically: Chisquare $/ \mathrm{df}=1,086<3 ;$ GFI $=0.932>0.9 ; \mathrm{CFI}=0.993>$ $0.9 ;$ TLI $=0.992>0.9 ;$ RMSEA $=0.015<0.08 ;$ PCLOSE $=$ $1,000>0.05$. The analysis results show that the research model is in agreement with the experimental data as shown in Figure 3.

As reported in Table 4, 8 research hypotheses were supported. Research Hypothesis 1 to 8, in which they hypothesized that the hedonism (TANHUONG), refreshment (THUGIAN), novelty (DOCDAO), involvement (THAMGIA), meaningfulness (YNGHIA), knowledge (KIENTHUC), local culture (VANHOA), surprising experience (BATNGO) components of a memorable tourism experience positively affects revisit intentions, was supported ( $p$-value $<0.001$ ). Among the memorable travel experience components, the relaxation component has the most substantial influence on future behavioral intentions (Standardized Regression Weights $=0.22$ ) .

That means that the more refreshed tourists feel during their trip, the more likely they are to return to their destination. Besides refreshments, novelty and hedonism are also two factors that strongly impact the intention to revisit CBT destinations of domestic tourists. Local cultural factors have the most insignificant influence on revisit intention to a destination of domestic tourists. In other words, the local cultural values or the friendliness of the locals in the destination did not play an essential role in making domestic tourists want to revisit these CBT destinations. The analysis results show that adverse feelings impact negatively revisiting intention, with $\mathrm{p}$-value $=0.291>0.05$, hypothesis $\mathrm{H} 9$ is rejected. Squared Multiple Correlations results show that the independent variable revisits intention (YDINH) has R2 = 66.8. Thus, the independent variables in the model explained $66.8 \%$ of the variation of the dependent variable.

Table 3: The reliability, convergence and discrimination of all scales

\begin{tabular}{|l|l|l|l|l|l|l|l|l|l|l|l|l|l|}
\hline & CR & AV E & MSV & $\begin{array}{l}\text { Y- } \\
\text { NGHIA }\end{array}$ & YDINH & $\begin{array}{l}\text { VAN- } \\
\text { HOA }\end{array}$ & $\begin{array}{l}\text { TAN- } \\
\text { HUONG }\end{array}$ & $\begin{array}{l}\text { BAT- } \\
\text { NG0 }\end{array}$ & $\begin{array}{l}\text { THAM- } \\
\text { GIA }\end{array}$ & $\begin{array}{l}\text { DOC- } \\
\text { DA0 }\end{array}$ & $\begin{array}{l}\text { THU- } \\
\text { GIAN }\end{array}$ & $\begin{array}{l}\text { KIEN- } \\
\text { THUC }\end{array}$ & $\begin{array}{l}\text { TIEU- } \\
\text { CUC }\end{array}$ \\
\hline YNGHIA & 0.857 & 0.599 & 0.339 & $\mathbf{0 . 7 7 4}$ & & & & & & & & \\
\hline YDINH & 0.879 & 0.646 & 0.336 & $0.548^{* * *}$ & $\mathbf{0 . 8 0 4}$ & & & & & & & & \\
\hline VANH0A & 0.839 & 0.566 & 0.336 & $0.442^{* * *}$ & $0.580^{* * *}$ & $\mathbf{0 . 7 5 2}$ & & & & & & & \\
\hline TANHUONG & 0.823 & 0.538 & 0.292 & $0.256^{* * *}$ & $0.540^{* * *}$ & $0.384^{* * *}$ & $\mathbf{0 . 7 3 4}$ & & & & & & \\
\hline BATNG0 & 0.846 & 0.647 & 0.147 & $0.185^{* *}$ & $0.339^{* * *}$ & $0.193^{* *}$ & 0.086 & $\mathbf{0 . 8 0 4}$ & & & & & \\
\hline THAMGIA & 0.846 & 0.648 & 0.339 & $0.582^{* * *}$ & $0.534^{* * *}$ & $0.418^{* * *}$ & $0.235^{* * *}$ & $0.251^{* * *}$ & $\mathbf{0 . 8 0 5}$ & & & & \\
\hline DOCDA0 & 0.832 & 0.623 & 0.289 & $0.379^{* * *}$ & $0.537^{* * *}$ & $0.351^{* * *}$ & $0.520^{* * *}$ & 0.090 & $0.331^{* * *}$ & $\mathbf{0 . 7 8 9}$ & & & \\
\hline THUGIAN & 0.819 & 0.601 & 0.331 & $0.352^{* * *}$ & $0.575^{* * *}$ & $0.540^{* * *}$ & $0.484^{* * *}$ & 0.062 & $0.304^{* * *}$ & $0.351^{* * *}$ & $\mathbf{0 . 7 7 5}$ & & \\
\hline KIENTHUC & 0.805 & 0.579 & 0.113 & $0.136^{*}$ & $0.336^{* * *}$ & $0.237^{* * *}$ & $0.130^{*}$ & $0.311^{* * *}$ & $0.122^{*}$ & $0.127 *$ & $0.141^{*}$ & $\mathbf{0 . 7 6 1}$ & \\
\hline TIEUCUC & 0.792 & 0.559 & 0.147 & -0.057 & $-0.137^{*}$ & -0.072 & -0.076 & $-0.384^{* *}$ & -0.035 & 0.007 & 0.017 & -0.045 & $\mathbf{0 . 7 4 8}$ \\
\hline
\end{tabular}




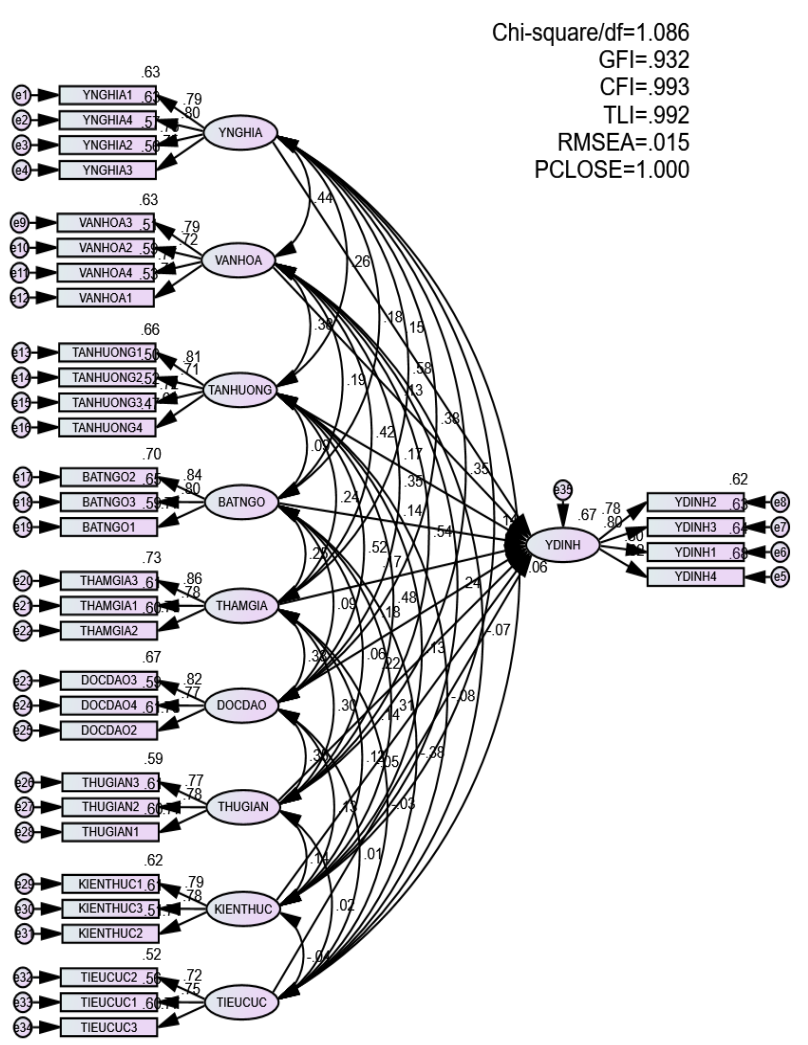

that combine tourism with charity or public activities for the locality.

Research shows that in CBT in Vietnam, the memorable components extend more than the memorable tourism experience components identified in previous studies with different contexts. There are nine memorable tourism experience components identified in the community tourism context (Hedonism, refreshment, involvement, novelty, meaningfulness, knowledge, local culture, surprising experience, adverse feeling). This number is more than studies conducted with the mass tourism context in large cities (7 components - Kim et al; 8 components Coudounaris et al.), tourism yoga calendar (5 components Sharma and Nayak), national park tourism (6 components Bigne et al.) [17], [9], [26], [5] ... This shows the travel experience at CBT destinations in Vietnam is quite rich. It makes a deep impression on domestic tourists.

This study also has the same conclusion as the study of Coudounaris et al. that adverse feelings-related tourism experiences have no impact on revisit intention of tourists [9]. This result can be explained by the "rose view" theory [21]. These researchers suggest that a person's postexperience perception is more favorable than the experience he or she has. Revisit intentions in tourism are usually medium-term or long-term intentions.

Figure 2: Standardized linear structural equation model

Table 4: Testing of hypotheses based on SEM

\begin{tabular}{|c|c|c|c|c|c|c|}
\hline \multicolumn{3}{|c|}{ Hypotheses path } & \multirow{2}{*}{$\begin{array}{c}\begin{array}{c}\text { Regression } \\
\text { Weights }\end{array} \\
.110\end{array}$} & \multirow{2}{*}{$\begin{array}{c}\begin{array}{c}\text { Standardized } \\
\text { Regression } \\
\text { Weights }\end{array} \\
0.173\end{array}$} & \multirow{2}{*}{$\begin{array}{c}\text { P-value } \\
.002\end{array}$} & \multirow{2}{*}{$\begin{array}{c}\text { Hypotheses } \\
\text { Supported }\end{array}$} \\
\hline H1: Hedonism & $\Rightarrow$ & Revisit intention & & & & \\
\hline H2: Refreshment & $\Rightarrow$ & Revisit intention & .140 & 0.22 & $* * *$ & Supported \\
\hline H3: Novelty & $\Rightarrow$ & Revisit intention & .127 & 0.182 & $* * *$ & Supported \\
\hline H4: Involvement & $\Rightarrow$ & Revisit intention & .115 & 0.169 & .002 & Supported \\
\hline H5: Meaningfulness & $\Rightarrow$ & Revisit intention & .115 & 0.154 & .005 & Supported \\
\hline H6: Knowledge & $\Rightarrow$ & Revisit intention & .094 & 0.145 & .001 & Supported \\
\hline H7: Local Culture & $\Rightarrow$ & Revisit intention & .086 & 0.129 & .020 & Supported \\
\hline H8: Surprising experience & $\Rightarrow$ & Revisit intention & .099 & 0.136 & .005 & Supported \\
\hline H9: Adverse feeling & $\Rightarrow$ & Revisit intention & -.047 & -0.148 & .291 & Not supported \\
\hline
\end{tabular}

\section{F. Discussion}

Research with community-based tourism in Vietnam has added two new indicators for the Meaningfulness and Local Culture components. The item VANHOA4 about local cuisine reflects the difference in CBT experience in Vietnam when the culinary element is emphasized. Tourists care about food, not new in tourism research, but this result reflects that tourists view cuisine as an important recognition and memory sign of local culture. The item YNGHIA4, about tourists being inspired through tourism experiences, also proves the characteristics of culture, landscape, activities, festivals... in CBT have great inspirational power. It will be an advantage in developing tourism experiences
After a while, due to the "rose view" effect, although tourists still remember the existence of these adverse feelings, they are much less sad, stressed, or embarrassed than at the time it occurred. Therefore, this component had little or no influence on their intention to revisit.

In the results of this study, the local cultural composition has the slightest influence on tourists' intention to revisit. In previous studies, the local cultural component is always one that significantly impacts the intention to revisit. The author believes that the cause of this difference is that the survey participants in the study are domestic tourists. With the expansion of media and transport, most people in all regions of Vietnam have access to simulated cultural experiences of 
other localities. Traditional costumes appear on stage in costume rental shops. Folk games are held in schools, team building programs. Local cuisine can be found in restaurants ... The impact of local culture on the revisit intention of international tourists can be more significant because they do not have many opportunities to access these simulated cultural experiences.

\section{Conclusion and Future Research}

Based on the obtained results, the author gives some solutions and recommendations for the design of community tourism experiences in Vietnam, specifically as follows:

First, local communities and tourism service providers need to design their own travel experiences. CBT experience designs in many destinations are simple and often copied from other successful destinations. It will reduce the uniqueness, making tourists less eager for experiences at the destination.

Second, when designing tourism experiences, it is necessary to focus on those components that have the most substantial impact on tourists' intention to revisit. Refreshment, novelty, and hedonism are these factors in CBT in Vietnam. This conclusion shows that CBT destinations need to focus on designing experiences that enhance these three dimensions to create memorable tourism experiences and increase tourists' revisit intention. To do this, the local community and travels service providers need to consult with experienced design experts and the practical knowledge of visitors.

Third, experience designs need to be continuously improved to deliver the best experiences for tourists and be diversified to suit each tourist group. For example, domestic and international tourists' needs will undoubtedly have many differences, so the design of experiences must also be different.

One of the most significant limitations of the study is that the sample size is not substantial, and the scope of the study is still small.; the survey participants are domestic tourists. The study also did not explore the relationship between memorable tourism experiences and tourists' intention to revisit among different groups of tourists in terms of age, size, cost of travel... The author will expand the research scope and sample size in future studies to retest the obtained results and add control variables to the model.

\section{REFERENCES}

[1] Ajzen, I., \& Driver, B. L. (1992). Application of the Theory of Planned Behavior to Leisure Choice. Journal of Leisure Research, 24(3), 207-224.

[2] Arnould, E., and L. Price. (1993). "River Magic: Extraordinary Experience and the Extended Service Encounter." Journal of Consumer Research, 20: 24-45.

[3] Ayazlar, G., \& Arslan Ayazlar, R. (2017). A Cross-cultural Investigation of Tourists' Memorable Experiences between Two Nationalities. Almatourism - Journal of Tourism, Culture, and Territorial Development, 8(15), 136-151.

[4] Baker, D. A., and J. L. Crompton. 2000. "Quality, Satisfaction, and Behavioral Intentions." Annals of Tourism Research 27 (3): 785-804.

[5] Bigne, E., Fuentes-Medina, M. L., \& Morini-Marrero, S. (2020). Memorable tourist experiences versus ordinary tourist experiences are analyzed through user-generated content. Journal of Hospitality and Tourism Management, 45, 309-318.

[6] Chandralal và Valenzuela (2015), Memorable Tourism Experiences: Scale Development, Contemporary Management Research, Vol. 11, No. 3, 291-310.
[7] Chandralal, L., \& Valenzuela, F. (2013). Exploring memorable tourism experiences: Antecedents and behavioral outcomes. Journal of Economics, Business, and Management, 1(2), 177-181.

[8] Chu Hieu (2019), Community-based tourism development in Cao Bang, Ethnic and mountainous photojournalism, accessed March 12, 2020, https://dantocmiennui.vn/du-lich/cao-bang-phat-trien-du-lichcong-dong/230455.html.

[9] Coudounaris, D. \& Sthapit, E (2017) Antecedents of memorable tourism experience related to behavioral intentions, Psychology \& Marketing, Volume34, Issue 12, 1084-1093.

[10] Doan Van Tuan (2015), To strongly develop community-based tourism in Vietnam, Economics and Forecast No. 7, pp.57-59.

[11] Han Chen, Imran Rahman (2018) Cultural tourism: An analysis of engagement, cultural contact, memorable tourism experience, and destination loyalty, Tourism Management Perspectives 26 (2018) 153-163.

[12] Jang, S., \& Feng, R. (2007). Temporal destination revisit intention: The effects of novelty seeking and satisfaction. Tourism Management, $28(2), 580-590$.

[13] Kerstetter, D., \& Cho, M. (2004). Tourists' information search behavior: The role of prior knowledge and perceived credibility. Annals of Tourism Research, 31(4), 961-985.

[14] Kim, J.-H., Ritchie, J. R. B., \& Tung, V. W. S. (2010). The Effect of Memorable Experience on Behavioral Intentions in Tourism: A Structural Equation Modeling Approach. Tourism Analysis, 15(6), 637-648.

[15] Kim, J.-H. (2017). The Impact of Memorable Tourism Experiences on Loyalty Behaviors: The Mediating Effects of Destination Image and Satisfaction. Journal of Travel Research, 57(7), 856-870.

[16] Kim, J. H., Ritchie, J. R. B., \& McCormick, B. (2012). Development of a scale to measure memorable tourism experiences. Journal of Travel Research, 51(1), 12-25.

[17] Kim, J. H., \& Ritchie, J. R. B. (2013). Cross-cultural validation of a memorable tourism experience scale (MTES). Journal of Travel Research, 53(3), 323-335.

[18] Kim, J., Ritchie, J. R. B., \& Tung, W. S. V. (2010). The effect of memorable experience on behavioral intentions in tourism: A structural equation modeling approach. Tourism Analysis, 15, 637648.

[19] Kozak, M. (2001) Repeaters' Behavior at Two Distinct Destinations. Annals of Tourism Research, 28, 784-807.

[20] Larsen, S. (2007). "Aspects of a Psychology of the Tourist Experience." Scandinavian Journal of Hospitality \& Tourism, 7 (1): 7 18.

[21] Mitchell, T. R., Thompson, L., Peterson, E., \& Cronk, R. (1997). Temporal Adjustments in the Evaluation of Events: The "Rosy View." Journal of Experimental Social Psychology, 33(4), 421-448.

[22] Nicole Häusler, Wolfgang Strasdas (2002), Training Manual for Community Based Tourism, InWent Capacity Building International, Germany, 2002

[23] Otto, J.E., \& Ritchie, J. R. B. (1996). The service experience in tourism. Tourism Management, 17(3), 165-174.

[24] Pine và Gilmore (1998), The Experience Economy: Work Is Theatre and Every Business a Stage, Harvard Business School Press, Boston.

[25] Quinlan Cutler, S. \& Carmichael, B. (2010) The dimensions of the tourist experience. In M. Morgan, P. Lugosi \& B. Ritchie (Eds) The Tourism and Leisure Experience: Consumer and Managerial Perspectives (pp. 3-26). Bristol: Channel View Publications.

[26] Sharma, P., \& Nayak, J. K. (2019). Examining experience quality as the determinant of tourist behavior in niche tourism: an analytical approach. Journal of Heritage Tourism, 1-17.

[27] Sthapit (2013) Tourists' perceptions of memorable experiences: testing the Memorable Tourism Experience scale (MTEs) among tourists to Rovaniemi, Lapland, pro graduate thesis.

[28] Tran Thi Mai An (2017), Ethnic community tourism in Vietnam: trends in adapting to the needs of cultural integration, Southeast Asian Studies, No. 12, pp.73-78

[29] Tung, V. W. S., \& Ritchie, J. R. B. (2011). Exploring the essence of memorable tourist experiences. Annals of Tourism Research, 38(4), $1367-1386$.

[30] Um, S., Chon, K., \& Ro, Y. (2006). Antecedents of revisit intention. Annals of Tourism Research, 33(4), 1141-1158.

[31] Zhang, H., Wu, Y., \& Buhalis, D. (2018). A model of perceived image, memorable tourism experiences, and revisit intention. Journal of Destination Marketing \& Management, 8, 326-336. 